\title{
Everolimus- and sirolimus-eluting stents in patients with and without ST-segment elevation myocardial infarction
}

\author{
M. A. Velders • A. J. van Boven • J. Brouwer • \\ P. C. Smits - A. W. J. van 't Hof • C. J. de Vries • \\ M. Queré • S. H. Hofma
}

Published online: 13 February 2014

(C) The Author(s) 2014. This article is published with open access at Springerlink.com

\begin{abstract}
Aims Everolimus-eluting stents (EES) were superior to sirolimus-eluting stents (SES) in a dedicated myocardial infarction trial, a finding that was not observed in trials with low percentages of ST-elevation myocardial infarction (STEMI). Therefore, this study sought to investigate the influence of clinical presentation on outcome after EES and SES implantation.

Methods A pooled population of 1602 randomised patients was formed from XAMI (acute MI trial) and APPENDIXAMI (all-comer trial). Primary outcome was cardiac mortality, MI and target vessel revascularisation at 2 years. Secondary endpoints included definite/probable stent thrombosis (ST). Adjustment was done using Cox regression.

Results In total, 902 EES and 700 SES patients were included, of which $44 \%$ STEMI patients (EES 455; SES 257) and $56 \%$ without STEMI (EES 447; SES 443). In the pooled population, EES and SES showed similar outcomes during followup. Moreover, no differences in the endpoints were observed after stratification according to presentation. Although a trend toward reduced early definite/probable ST was observed in EES compared with SES in STEMI patients, long-term ST rates were low and comparable.

Conclusions EES and SES showed a similar outcome during 2-year follow-up, regardless of clinical presentation. Long-
\end{abstract}

M. A. Velders $(\triangle) \cdot$ A. J. van Boven · J. Brouwer $\cdot$ C. J. de Vries • M. Queré $\cdot$ S. H. Hofma

Department of Cardiology, Medical Center Leeuwarden, PO Box 888, 8901 BR Leeuwarden, the Netherlands

e-mail: m.a.velders@lumc.nl

P. C. Smits

Department of Cardiology, Maasstad Hospital, Rotterdam, the Netherlands

A. W. J. van 't Hof

Department of Cardiology, Isala Clinics, Zwolle, the Netherlands term safety was excellent for both devices, despite wide inclusion criteria and a large sub-population of STEMI patients.

Keywords Drug-eluting stents $\cdot$ Percutaneous coronary intervention $\cdot$ Coronary artery disease

\section{Introduction}

Drug-eluting stents (DES) were designed to reduce the in-stent neointimal hyperplasia that commonly occurred in bare-metal stents (BMS). Indeed, first-generation DES (i.e. paclixateleluting stents (PES) and sirolimus-eluting stents (SES)) reduced the need for revascularisation procedures compared with BMS but were associated with higher rates of late stent thrombosis (ST), especially in complex patients such as those presenting with myocardial infarction (MI) [1-3].

Delayed arterial healing and stent malapposition were found to play a role in the higher ST rates after DES implantation in the setting of MI [4, 5]. Second-generation DES were designed to be safer and more effective through changes in stent design, polymer and anti-restenotic drugs. So far, second-generation everolimus-eluting stents (EES) have shown superior results to PES in a wide range of indications [6]. Compared with SES, EES have mostly shown comparable outcomes but improvements in ST rates have been observed [7-10]. In contrast, one dedicated trial of predominantly ST-segment elevation myocardial infarction (STEMI) patients showed superiority of EES over SES during short-term follow-up [11]. Long-term randomised data are scarce, especially in setting of STEMI.

This study sought to investigate the influence of clinical presentation on outcome of EES and SES during 2-year follow-up. 


\section{Methods}

Patient-level data from the randomised XAMI and APPENDIX-AMI trials were pooled to form the patient population. The design and results of these trials have been published previously [11, 12]. In short, XAMI (NTR1123, http://www.trialregister.nl/trialreg/admin/ctview.asp?TC= 1123) was a multicentre, clinical non-inferiority trial randomising 625 acute MI patients to EES (Xience V [Abbott Vascular, Santa Clara, California]) or SES (Cypher [Cordis, Bridgewater, New Jersey]) in a 2:1 ratio. To be enrolled, patients had to have STEMI or non-STEMI with an emergency indication for percutaneous coronary intervention (PCI). Exclusion criteria were: chronic total occlusion as target lesion; known allergy to sirolimus, everolimus, aspirin or clopidogrel; inability to obtain informed consent; life expectancy $<1$ year; or stent size required to treat lesion $>3$. $5 \mathrm{~mm}$.

APPENDIX-AMI (NTR3170, http://www.trialregister.nl/ trialreg/admin/rctview.asp? $\mathrm{TC}=3170$ ) was a single-centre open-label trial randomising 977 all-comer patients to EES and SES (ratio 1:1). The trial included all patients eligible for coronary revascularisation by PCI for any indication. Exclusion criteria were: known allergy for everolimus or sirolimus, aspirin or clopidogrel; inability or unwillingness to give informed consent; and anatomy in which stent implantation is deemed not technically possible.

Patients were pretreated with loading doses of aspirin and clopidogrel, in addition to intravenous heparin bolus of $5000 \mathrm{IE}$ in case of MI. Use of glycoprotein IIb/IIIa inhibitors, thrombus aspiration and balloon pre-dilatation were left up to the discretion of the operator. Aspirin was recommended for life and clopidogrel for a minimum of 1 year. Protocol-defined follow-up was performed after 30 days, 1 year and 2 years by questionnaires and telephone contact. Follow-up was gathered by research nurses in a blinded fashion. Event adjudication was performed by a blinded clinical event committee in XAMI. In APPENDIX-AMI, event adjudication was performed between physicians on a consensus basis in an unblinded fashion. The study protocols were approved by the local ethics committees of the participating centres and the trials were conducted according to the principles of the Declaration of Helsinki. All patients gave oral consent before enrolment and written informed consent after procedure.

\section{Definitions}

The primary endpoint was a composite of cardiac death, MI and target vessel revascularisation (TVR). MI was defined as a rise of creatine kinase $(\mathrm{CK})$ more than three times the upper

Table 1 Baseline characteristics

\begin{tabular}{|c|c|c|c|c|c|c|}
\hline \multirow[b]{2}{*}{ Variable } & \multicolumn{3}{|l|}{ STEMI } & \multicolumn{3}{|c|}{ Other indications } \\
\hline & $\operatorname{EES}(N=455)$ & $\operatorname{SES}(N=257)$ & $p$ value & $\operatorname{EES}(N=447)$ & $\operatorname{SES}(N=443)$ & $p$ value \\
\hline Age, years & $61.8 \pm 11.4$ & $62.4 \pm 11.5$ & 0.501 & $65.2 \pm 11.3$ & $65.1 \pm 11.1$ & 0.868 \\
\hline Male & $329(72.3 \%)$ & $194(75.5 \%)$ & 0.356 & $319(71.4 \%)$ & $319(72.0 \%)$ & 0.831 \\
\hline Diabetes mellitus & $41(9.1 \%)$ & $26(10.2 \%)$ & 0.612 & $73(16.9 \%)$ & $80(18.6 \%)$ & 0.492 \\
\hline Hypertension $^{\mathrm{a}}$ & $136(30.1 \%)$ & $81(31.8 \%)$ & 0.643 & $191(43.6 \%)$ & $223(51.5 \%)$ & 0.020 \\
\hline Hypercholesterolaemia ${ }^{\mathrm{b}}$ & $124(27.8 \%)$ & $60(23.8 \%)$ & 0.250 & $242(57.5 \%)$ & $246(57.9 \%)$ & 0.906 \\
\hline Current smoker & $232(51.3 \%)$ & $135(53.1 \%)$ & 0.642 & $121(27.6 \%)$ & $94(21.9 \%)$ & 0.051 \\
\hline Prior myocardial infarction & $32(7.0 \%)$ & $19(7.4 \%)$ & 0.858 & $100(22.6 \%)$ & $102(23.2 \%)$ & 0.844 \\
\hline Prior PCI & $19(4.2 \%)$ & $9(3.5 \%)$ & 0.653 & $81(18.2 \%)$ & $105(23.7 \%)$ & 0.046 \\
\hline Prior CABG & $4(0.9 \%)$ & $5(1.9 \%)$ & 0.221 & $47(10.5 \%)$ & $71(16.0 \%)$ & 0.016 \\
\hline Prior renal insufficiency & $8(1.8 \%)$ & $6(2.4 \%)$ & 0.596 & $49(11.8 \%)$ & $43(10.6 \%)$ & 0.598 \\
\hline Presenting diagnosis & & & & & & 0.072 \\
\hline - Stable angina & $0(0.0 \%)$ & $0(0.0 \%)$ & - & $251(56.2 \%)$ & $275(62.1 \%)$ & \\
\hline - Unstable angina or non-STEMI & $0(0.0 \%)$ & $0(0.0 \%)$ & - & $196(43.8 \%)$ & $168(37.9 \%)$ & \\
\hline - STEMI & $455(100 \%)$ & $257(100 \%)$ & - & $0(0.0 \%)$ & $0(0.0 \%)$ & - \\
\hline Symptoms to first medical contact (min) & $90(60-170)$ & $100(60-185)$ & 0.419 & - & - & \\
\hline First medical contact to balloon inflation ( $\mathrm{min}$ ) & $75(60-100)$ & $75(60-100)$ & 0.937 & - & - & \\
\hline
\end{tabular}

Data are expressed as mean $\pm \mathrm{SD}$, as number (percentage), or as median (interquartile range). $\mathrm{CABG}=$ coronary artery bypass grafting

${ }^{\text {a }}$ Blood pressure $140 / 90 \mathrm{~mm} \mathrm{Hg}$ or previous pharmacological treatment

b Total cholesterol $190 \mathrm{mg} / \mathrm{dl}$ or previous pharmacological treatment 
Table 2 Procedural characteristics

\begin{tabular}{|c|c|c|c|c|c|c|}
\hline \multirow[b]{2}{*}{ Variable } & \multicolumn{3}{|l|}{ STEMI } & \multicolumn{3}{|c|}{ Other indications } \\
\hline & $\operatorname{EES}(N=455)$ & $\operatorname{SES}(N=257)$ & $p$ value & $\operatorname{EES}(N=447)$ & $\operatorname{SES}(N=443)$ & $p$ value \\
\hline Target coronary lesion & & & 0.651 & & & 0.108 \\
\hline - Left main artery & $0(0.0 \%)$ & $1(0.4 \%)$ & & $26(5.9 \%)$ & $15(3.4 \%)$ & \\
\hline - Left anterior descending artery & $175(38.5 \%)$ & $104(40.5 \%)$ & & $195(44.0 \%)$ & $175(39.8 \%)$ & \\
\hline - Left circumflex artery & $86(18.9 \%)$ & $50(19.5 \%)$ & & $96(21.7 \%)$ & $124(28.2 \%)$ & \\
\hline - Right coronary artery & $192(42.3 \%)$ & $101(39.3 \%)$ & & $124(28.0 \%)$ & $124(28.2 \%)$ & \\
\hline - Bypass graft & $1(0.2 \%)$ & $1(0.4 \%)$ & & $2(0.5 \%)$ & $2(0.5 \%)$ & \\
\hline Multivessel disease & $206(45.3 \%)$ & $130(50.6 \%)$ & 0.173 & $249(55.8 \%)$ & $252(56.9 \%)$ & 0.751 \\
\hline Bifurcation intervention & $55(12.1 \%)$ & $37(14.4 \%)$ & 0.390 & $107(24.4 \%)$ & $98(22.4 \%)$ & 0.496 \\
\hline Heavy calcification & $26(5.8 \%)$ & $28(10.9 \%)$ & 0.013 & $62(14.0 \%)$ & $85(19.4 \%)$ & 0.032 \\
\hline Lesion type $\mathrm{B} 2 / \mathrm{C}$ & $300(66.7 \%)$ & $171(67.6 \%)$ & 0.803 & $245(55.4 \%)$ & $241(55.0 \%)$ & 0.903 \\
\hline Visible thrombus & $383(84.5 \%)$ & $223(87.1 \%)$ & 0.352 & $49(11.1 \%)$ & $39(8.9 \%)$ & 0.276 \\
\hline Thrombosuction & $250(54.9 \%)$ & $142(55.3 \%)$ & 0.937 & $11(2.5 \%)$ & $6(1.4 \%)$ & 0.222 \\
\hline Total stent length (mm) & $25.3 \pm 14.7$ & $27.7 \pm 16.5$ & 0.046 & $28.2 \pm 18.9$ & $28.2 \pm 16.0$ & 0.986 \\
\hline Max stent diameter (mm) & $3.1 \pm 0.4$ & $3.1 \pm 0.3$ & 0.676 & $3.1 \pm 0.6$ & $3.1 \pm 0.5$ & 0.436 \\
\hline No. of stents/patients & $1.4 \pm 0.7$ & $1.4 \pm 0.7$ & 0.396 & $1.5 \pm 0.7$ & $1.5 \pm 0.8$ & 0.475 \\
\hline Glycoprotein IIb/IIIa inhibitor treatment & $346(76.0 \%)$ & $196(76.3 \%)$ & 0.947 & $98(22.3 \%)$ & $82(18.7 \%)$ & 0.181 \\
\hline Postprocedural TIMI flow grade 3 & $431(94.9 \%)$ & $238(92.6 \%)$ & 0.206 & $428(98.2 \%)$ & $420(97.0 \%)$ & 0.262 \\
\hline
\end{tabular}

Data are expressed as number (percentage) or as mean $\pm \mathrm{SD}$

TIMI thrombolysis in myocardial infarction

limit of normal along with a rise in CK-MB with recurrent symptoms and/or new electrocardiographic changes. In acute coronary syndrome patients, re-infarction within $48 \mathrm{~h}$ after index procedure was defined as a re-elevation of $\mathrm{CK}$ of $>1.5$ times the previous value with elevation of CK-MB, along with recurrent symptoms and/or new electrocardiographic changes. MI around coronary artery bypass grafting required a CK rise of $>5$ times the upper limit of normal. TVR was defined as any repeat percutaneous or surgical intervention on any segment of the target vessel. Other secondary endpoints included the

Table 3 Clinical endpoints at 2 years

\begin{tabular}{|c|c|c|c|c|c|c|}
\hline \multirow[b]{2}{*}{ Variable } & \multicolumn{3}{|l|}{ STEMI } & \multicolumn{3}{|c|}{ Other indications } \\
\hline & $\operatorname{EES}(N=450)$ & $\operatorname{SES}(N=257)$ & $p$ value & $\operatorname{EES}(N=436)$ & $\operatorname{SES}(N=432)$ & $p$ value \\
\hline Primary composite endpoint ${ }^{\mathrm{a}}$ & $27(6.0)$ & $24(9.3)$ & 0.099 & $51(11.7)$ & $46(10.6)$ & 0.624 \\
\hline \multicolumn{7}{|l|}{ Mortality } \\
\hline - All-cause & $15(3.3)$ & $14(5.4)$ & 0.173 & $25(5.7)$ & $19(4.4)$ & 0.370 \\
\hline - Cardiac & $10(2.2)$ & $8(3.1)$ & 0.470 & $16(3.7)$ & $10(2.3)$ & 0.242 \\
\hline Myocardial infarction & $6(1.3)$ & $5(1.9)$ & 0.527 & $6(1.4)$ & $8(1.9)$ & 0.578 \\
\hline Target vessel revascularisation & $15(3.3)$ & $13(5.1)$ & 0.258 & $33(7.6)$ & $32(7.4)$ & 0.928 \\
\hline Target lesion revascularisation & $7(1.6)$ & $3(1.2)$ & 0.674 & $19(4.4)$ & $17(3.9)$ & 0.755 \\
\hline \multicolumn{7}{|l|}{ Stent thrombosis } \\
\hline - Definite & $3(0.7)$ & $0(0.0)$ & 0.190 & $3(0.7)$ & $4(0.9)$ & 0.695 \\
\hline - Definite/probable & $6(1.3)$ & $7(2.7)$ & 0.186 & $4(0.9)$ & $5(1.2)$ & 0.727 \\
\hline - Early & $3(0.7)$ & $6(2.3)$ & 0.057 & $1(0.2)$ & $2(0.5)$ & 0.558 \\
\hline - Late & $2(0.4)$ & $1(0.4)$ & 0.913 & $0(0.0)$ & $1(0.2)$ & 0.315 \\
\hline - Very late & $1(0.2)$ & $0(0.0)$ & 0.449 & $3(0.7)$ & $2(0.5)$ & 0.661 \\
\hline
\end{tabular}

Values are expressed as number (percentage)

${ }^{\text {a }}$ Cardiac mortality, myocardial infarction and target vessel revascularisation 


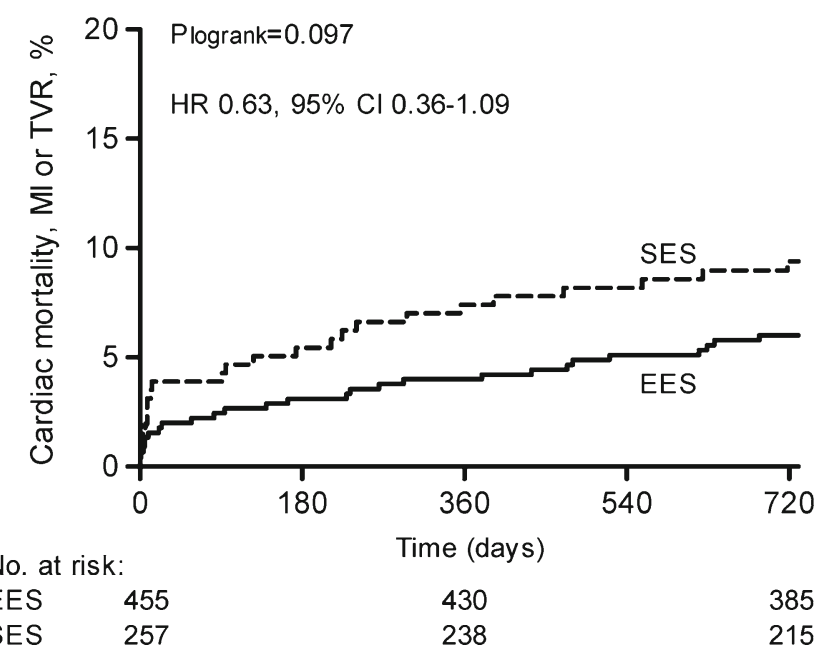

Fig. 1 Two-year primary outcome according to randomised stent in STEMI patients

individual components of the composite endpoint, target lesion revascularisation (TLR) and definite or probable ST. TLR was defined as any repeat intervention or bypass grafting of the target lesion previously treated with stenting along with the $5 \mathrm{~mm}$ proximal or distal vessel. ST was defined in accordance with the Academic Research Consortium definitions [13].

\section{Statistical analyses}

Comparisons were made according to randomised treatment and presentation with or without STEMI. Continuous variables are presented as means with standard deviations or medians with interquartile range (IQR) and were compared using Student's $t$-test. Categorical variables are expressed as counts and percentages and were compared by means of Pearson's $\chi^{2}$ test. All statistical tests were 2-tailed and a $p$-value $<0.05$ was considered statistically significant. Timeto-event analyses were performed using Kaplan-Meier curves, which were compared using log-rank tests. To adjust for unbalanced baseline characteristics, Cox proportional hazards analyses were performed. The proportional hazards assumption was investigated visually. Adjusted effect sizes were calculated for primary and secondary endpoints with a p-value less than 0.10 as judged by log rank test. Adjustment was performed for characteristics significantly differing between groups $(p<0.05)$, which were incorporated in the multivariable models. Analyses were repeated with a variable stating the trial the patient originated from, to evaluate the influence of individual trials on the results.

To avoid dropping of events due to missing baseline information, multiple imputation was performed for the baseline variables that were included in the multivariable models: presence of heavy calcification was unknown in four patients (three EES and one SES) and total stent length was unknown in four patients (three EES and one SES). Reasons for missing data were unknown and assumed to be random. Total stent length was log transformed to meet the assumption for normal distribution. Missing data values were imputed for heavy calcification and total stent length using the following predictors: age, gender, cardiac risk factors, cardiac history, renal insufficiency, indication for PCI, target lesion, lesion type, number of vessel disease, heavy calcification, total stent length, max stent diameter, and number of stents per patient. Twenty imputed datasets were created and Cox proportional hazards analyses were performed on the pooled datasets [14]. Analyses were performed using IBM SPSS version 21.

\section{Results}

In total, 1602 patients were randomised in the XAMI and APPENDIX-AMI trials, of which 902 to EES and 700 to SES. Two-year follow-up data were available for 1575 patients $(98.3 \%)$. The presenting diagnosis was stable angina in
Fig. 2 Definite/probable stent thrombosis with landmark analysis at 30-days in STEMI population

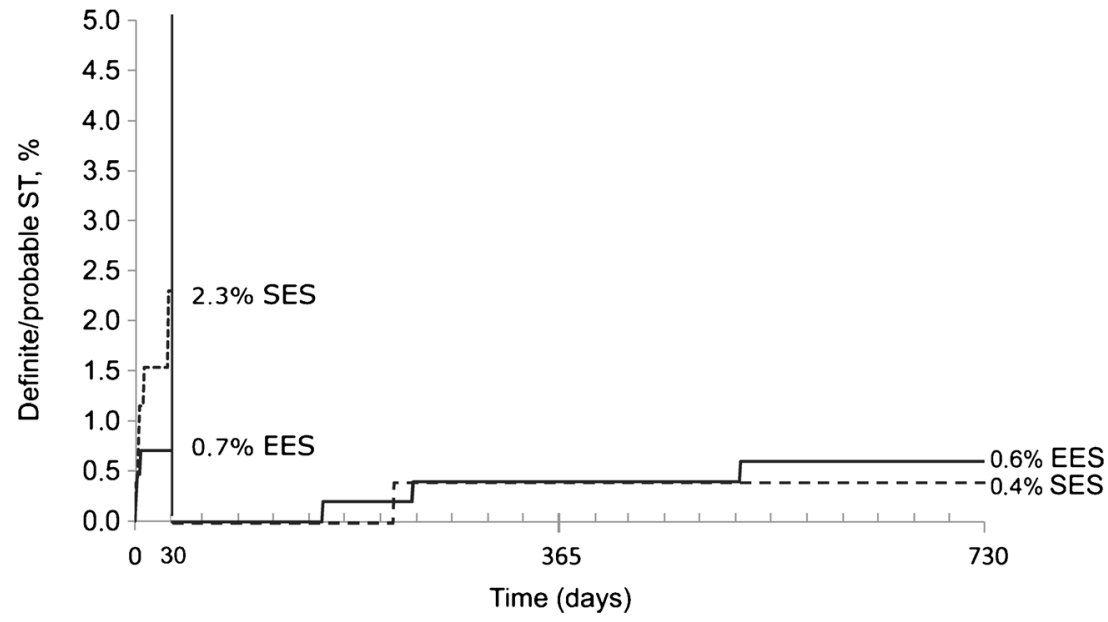




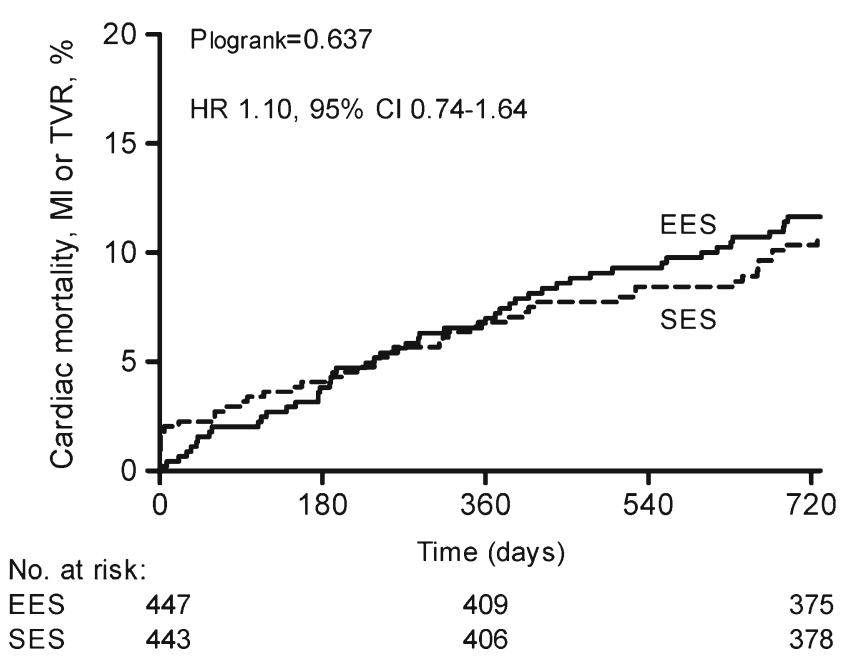

Fig. 3 Two-year primary outcome according to randomised stent in patients without STEMI

526 patients $(32.8 \%)$, unstable angina or non-STEMI in 364 patients $(22.7 \%)$ and STEMI in 712 patients $(44.4 \%)$. After pooling of the two trials, the primary endpoint occurred in $8.8 \%$ of EES patients vs. $10.2 \%$ of SES patients during 2year follow-up in the overall population, HR $0.86(95 \% \mathrm{CI}$ $0.62-1.18), p=0.347$. Secondary endpoints were also balanced between the groups.

\section{Stratification on presenting diagnosis}

STEMI patients were younger than patients without STEMI and more likely to smoke but had lower rates of comorbidity and other risk factors (Table 1). Coronary thrombus was more common in STEMI, but rates of heavy calcification, bifurcations and multivessel disease were lower. Stent length and number of stents used were also lower in STEMI, but stent diameter was slightly larger. Finally, glycoprotein IIb/IIIa inhibitor use was more common in STEMI while TIMI 3 flow after procedure was less often achieved. During 2-year follow- up, STEMI patients showed lower rates of the primary endpoint (7.2\% vs. $11.2 \%, p=0.007)$ and TLR ( $1.4 \%$ vs. $4.1 \%$, $p=0.001)$ compared with patients without STEMI.

In the STEMI population, EES showed less calcified lesions and total stent length was shorter compared with SES (Table 2). During 2-year follow-up, randomisation to EES resulted in a similar primary endpoint rate (unadjusted HR 0.63, $95 \%$ CI 0.36-1.09, $p=0.097$, adjusted HR 0.66, $95 \%$ CI 0.38-1.15, $p=0.141$ ) compared with SES (Table 3, Fig. 1). A trend was observed for reduced early definite/probable ST in EES. However, long-term ST rates were low and similar (Fig. 2). At 1-year, aspirin (or coumadin) compliance was $94.8 \%$ in EES versus $91.5 \%$ in SES $(p=0.092)$. Thienopyridine compliance was $95.6 \%$ in EES versus $91.8 \%$ in SES $(p=0.040)$. Two patients were not on dual antiplatelet therapy at the time of ST: 1 EES and 1 SES patient, both suffering probable ST.

In the population without STEMI, EES patients showed lower rates of hypertension, prior PCI, bypass grafting and heavy calcification compared with SES patients (Tables 1 and 2). At 2 years, EES and SES showed similar rates of the primary endpoint (HR 1.10, $95 \%$ CI $0.74-1.64, p=0.637$ ) (Table 3, Fig. 3). Other secondary endpoints were also balanced. Definite/probable ST rates were low and similar between the groups (Fig. 4). Aspirin compliance during 1 year was $97.6 \%$ in EES and $99.3 \%$ in SES $(p=0.047)$. Thienopyridine compliance was $96.8 \%$ in EES and $97.5 \%$ in $\operatorname{SES}(p=0.518)$.

The $p$-value for interaction between randomised stent and presenting diagnosis (STEMI vs. other) was 0.104 (HR 1.76, $95 \%$ CI 0.89-3.46) for the primary endpoint.

\section{Discussion}

The present pooled analysis of the randomised XAMI and APPENDIX-AMI trials provided 2-year outcome data of EES
Fig. 4 Definite/probable stent thrombosis with landmark analysis at 30-days in population without STEMI

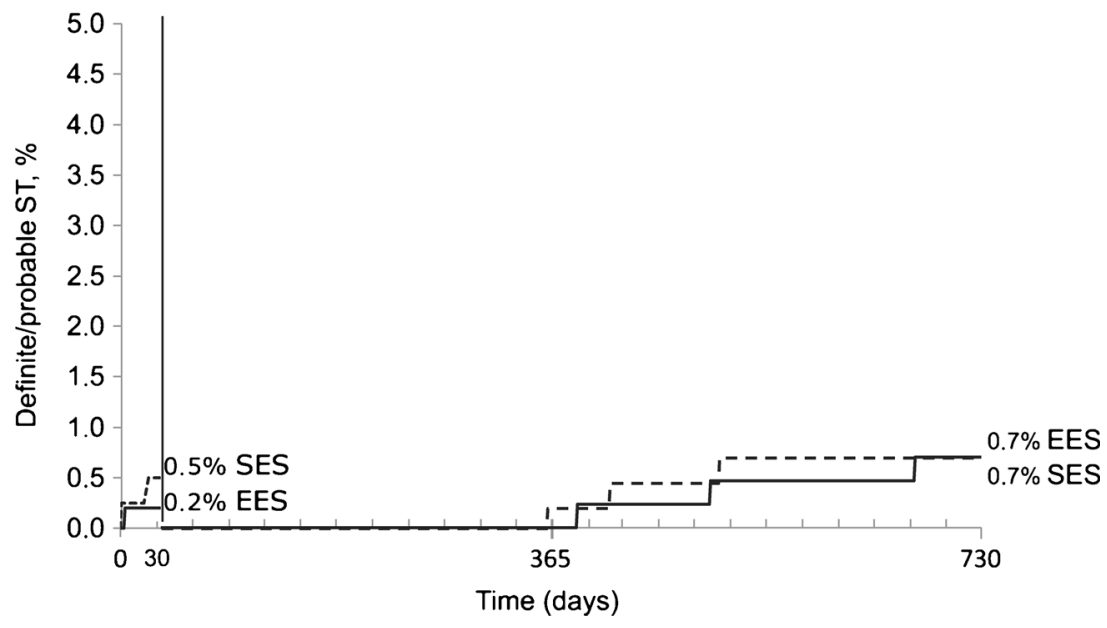


and SES according to clinical presentation. The performance of the first- and second-generation DES was found to be similar and independent of clinical presentation. Importantly, despite wide inclusion criteria and a large sub-population of STEMI patients, both devices showed a comparable safety at long-term follow-up.

Implantation of first-generation DES in the previously off-label indication of acute MI was controversial until publication of the HORIZONS-AMI trial, which confirmed the safety and efficacy of PES compared with BMS in primary PCI [15]. Superiority of second-generation EES over PES in acute coronary syndromes has been established but data comparing EES with previous golden standard SES are less abundant, especially in setting of STEMI [16]. In SORT OUT IV, EES and SES showed comparable outcomes up to 2 years, with the exception of a lower rate of definite ST in EES patients [7]. However, only $10 \%$ of patients presented with STEMI. The other major trials that compared EES and SES showed no differences in outcome in up to 3 years of follow-up [8-10]. Also in these trials, the STEMI population was strongly underrepresented, making randomised data of EES and SES in STEMI patients scarce beyond 1 year. In contrast, almost half the patients included in the current study presented with STEMI.

In the STEMI population of the present study, event rates were lower than in the population without STEMI, likely explained by the generally less complex thrombotic lesions in STEMI. Although EES appeared to perform slightly better than SES, no significant differences in the primary outcome measure were observed. Nonetheless, a strong trend toward reduced early definite/probable ST hinted at a possible advantage of EES over SES in the early phase after MI. In contrast, clinical outcomes were balanced between EES and SES in patients presenting with a diagnosis other than STEMI, which is in accordance with previous trials [8-10].

Findings observed in the STEMI population were comparable with reports of the EXAMINATIONS trial, in which EES use resulted in a lower rate of early definite/probable ST compared with BMS in STEMI patients [17]. At 1-year, the definite/probable ST rate was $0.9 \%$ in the EES group, comparable with the $1.1 \%$ rate observed in this study. Additionally, Kalesan et al. performed a propensity matched comparison of EES and SES in ACS patients and found a reduction in both the primary endpoint and ST during 3-year follow-up [18].

Important differences of EES compared with SES are the thin strut design and the biocompatible polymer. In ex-vivo and in-vivo models, thin struts were less thrombogenic and the slim design of EES has been associated with faster endothelialisation compared with SES $[19,20]$. Also, the biocompatible polymer of EES may be associated with a reduced long-term inflammatory response. While the current study found reassuringly low rates of ST in both DES, very longterm monitoring is necessary to establish a potential benefit of EES over SES. In the TYPHOON trial, SES showed a late 'catch-up' phenomenon for ST, i.e. the relatively low early ST rates were abolished by higher very late ST rates compared with BMS in STEMI patients during 4 years of follow-up [21].

Although the polymer applied in EES is more biocompatible than the SES polymer coating, additional improvement may be achieved with a biodegradable polymer coating. The COMFORTABLE AMI trial compared biolimus-eluting stents with BMS in STEMI patients but did not find a reduction in 1-year definite/probable ST [22]. However, long-term follow-up will have to show if STEMI patients benefit from DES with biodegradable polymer, as the main effect of a biodegradable polymer in reducing ST becomes evident after 1 year [23].

\section{Limitations}

Our study is limited by its post hoc nature and therefore findings should be considered hypothesis generating. XAMI included only patients with acute MI, while APPENDIX-AMI included all-comer patients. Furthermore, the randomisation rate differed between XAMI (2:1) and APPENDIX-AMI (1:1) which created baseline misbalance between the groups, although multivariable corrections were performed to adjust for these differences. Finally, the analysis was underpowered to detect differences in the ST rates.

\section{Conclusions}

The present pooled analysis of the XAMI and APPENDIXAMI trials found similar outcomes between EES and SES during 2 years of follow-up, regardless of clinical presentation. Long-term ST rates were reassuringly low in both stent types.

Funding The Cardiology Research Foundation of the Medical Center Leeuwarden received an unrestricted research grant from Abbott Vascular. The Cardiology Research Foundation of the Maasstad Hospital received institutional research grants from Abbott Vascular and Terumo.

Conflicts of interest Dr. Smits has received speaker fees from Abbott Vascular. Dr. van't Hof has received speaker fees from Merck Sharp \& Dohme and IrokoCardio and is on the advisory board of AstraZeneca, The Medicines Company, Daiichi Sankyo, and Lilly. All other authors have reported that they have no relationships relevant to the contents of this paper to disclose.

Open Access This article is distributed under the terms of the Creative Commons Attribution License which permits any use, distribution, and reproduction in any medium, provided the original author(s) and the source are credited. 


\section{References}

1. Kirtane AJ, Gupta A, Iyengar S, et al. Safety and efficacy of drugeluting and bare metal stents: comprehensive meta-analysis of randomized trials and observational studies. Circulation. 2009;119: 3198-206.

2. De Luca G, Dirksen MT, Spaulding C, et al. Drug-eluting vs baremetal stents in primary angioplasty: a pooled patient-level metaanalysis of randomized trials. Arch Intern Med. 2012;172:611-21.

3. Brodie B, Pokharel Y, Fleishman N, et al. Very late stent thrombosis after primary percutaneous coronary intervention with bare-metal and drug-eluting stents for ST-segment elevation myocardial infarction: a 15-year single-center experience. J Am Coll Cardiol Intv. 2011;4:30-8.

4. Nakazawa G, Finn AV, Joner M, et al. Delayed arterial healing and increased late stent thrombosis at culprit sites after drug-eluting stent placement for acute myocardial infarction patients: an autopsy study. Circulation. 2008;118:1138-45.

5. Hassan AK, Bergheanu SC, Stijnen T, et al. Late stent malapposition risk is higher after drug-eluting stent compared with bare-metal stent implantation and associates with late stent thrombosis. Eur Heart J. 2010;31:1172-80.

6. Smits PC, Kedhi E, Royaards KJ, et al. 2-year follow-up of a randomized controlled trial of everolimus- and paclitaxel-eluting stents for coronary revascularization in daily practice. COMPARE (Comparison of the everolimus eluting XIENCE-V stent with the paclitaxel eluting TAXUS LIBERTÉ stent in all-comers: a randomized open label trial). J Am Coll Cardiol. 2011;58:11-8.

7. Jensen LO, Thayssen P, Christiansen EH, et al. 2-year patient-related versus stent-related outcomes: the SORT OUT IV (Scandinavian Organization for Randomized Trials With Clinical Outcome IV) Trial. J Am Coll Cardiol. 2012;60:1140-7.

8. Byrne RA, Kastrati A, Massberg S, et al. Biodegradable polymer versus permanent polymer drug-eluting stents and everolimus- versus sirolimus-eluting stents in patients with coronary artery disease: 3year outcomes from a randomized clinical trial. J Am Coll Cardiol. 2011;58:1325-31.

9. Kimura T, Morimoto T, Natsuaki M, et al. Comparison of everolimuseluting and sirolimus-eluting coronary stents: 1-year outcomes from the Randomized Evaluation of Sirolimus-eluting Versus Everolimuseluting stent Trial (RESET). Circulation. 2012;126:1225-36.

10. Park KW, Chae IH, Lim DS, et al. Everolimus-eluting versus sirolimus-eluting stents in patients undergoing percutaneous coronary intervention: the EXCELLENT (Efficacy of Xience/Promus Versus Cypher to Reduce Late Loss After Stenting) randomized trial. J Am Coll Cardiol. 2011;58:1844-54.

11. Hofma SH, Brouwer J, Velders MA, et al. Second-generation everolimus-eluting stents versus first-generation sirolimus-eluting stents in acute myocardial infarction. 1-year results of the randomized XAMI (XienceV Stent vs. Cypher Stent in Primary PCI for Acute Myocardial Infarction) trial. J Am Coll Cardiol. 2012;60:381-7.
12. Velders MA, Hofma SH, Brouwer J, et al. Two-year results of an open-label randomized comparison of everolimus-eluting stents and sirolimus-eluting stents. PLoS ONE. 2013:e64424. doi:10.1371/ journal.pone.0064424.

13. Cutlip DE, Windecker S, Mehran R, et al. Clinical end points in coronary stent trials: a case for standardized definitions. Circulation. 2007;115:2344-51.

14. Sterne JA, White IR, Carlin JB, et al. Multiple imputation for missing data in epidemiological and clinical research: potential and pitfalls. BMJ. 2009;338:b2393. doi:10.1136/bmj.b2393.

15. Stone GW, Witzenbichler B, Guagliumi G, et al. Heparin plus a glycoprotein $\mathrm{IIb} / \mathrm{III} a$ inhibitor versus bivalirudin monotherapy and paclitaxel-eluting stents versus bare-metal stents in acute myocardial infarction (HORIZONS-AMI): final 3-year results from a multicentre, randomised controlled trial. Lancet. 2011;377: 2193-204.

16. Planer D, Smits PC, Kereiakes DJ, et al. Comparison of everolimusand paclitaxel-eluting stents in patients with acute and stable coronary syndromes: pooled results from the SPIRIT (A Clinical Evaluation of the XIENCE V Everolimus Eluting Coronary Stent System) and COMPARE (A Trial of Everolimus-Eluting Stents and Paclitaxel-Eluting Stents for Coronary Revascularization in Daily Practice) Trials. J Am Coll Cardiol Intv. 2011;4:1104-15.

17. Sabate M, Cequier A, Iñiguez A, et al. Everolimus-eluting stent versus bare-metal stent in ST-segment elevation myocardial infarction (EXAMINATION): 1 year results of a randomised controlled trial. Lancet. 2012;380:1482-90.

18. Kalesan B, Stefanini GG, Räber L, et al. Long-term comparison of everolimus- and sirolimus-eluting stents in patients with acute coronary syndromes. J Am Coll Cardiol Intv. 2012;5:145-54.

19. Kolandaivelu K, Swaminathan R, Gibson WJ, et al. Stent thrombogenicity early in high-risk interventional settings is driven by stent design and deployment and protected by polymer-drug coatings. Circulation. 2011;123:1400-9.

20. Joner M, Nakazawa G, Finn AV, et al. Endothelial cell recovery between comparator polymer-based drug-eluting stents. J Am Coll Cardiol. 2008;52:333-42.

21. Spaulding C, Teiger E, Commeau P, et al. Four-year follow-up of TYPHOON (trial to assess the use of the CYPHer sirolimus-eluting coronary stent in acute myocardial infarction treated with BallOON angioplasty). J Am Coll Cardiol Intv. 2011;4:14-23.

22. Räber L, Kelbæk H, Ostojic M, et al. Effect of biolimus-eluting stents with biodegradable polymer vs bare-metal stents on cardiovascular events among patients with acute myocardial infarction: the COMFORTABLE AMI randomized trial. JAMA. 2012;308:777-87.

23. Stefanini GG, Byrne RA, Serruys PW, et al. Biodegradable polymer drug-eluting stents reduce the risk of stent thrombosis at 4 years in patients undergoing percutaneous coronary intervention: a pooled analysis of individual patient data from the ISAR-TEST 3, ISARTEST 4, and LEADERS randomized trials. Eur Heart J. 2012;33: 1214-22. 